\title{
Low-dose eribulin mesylate exerts antitumor effects in gastric cancer by inhibiting fibrosis via the suppression of epithelial-mesenchymal transition and acts synergistically with 5-fluorouracil
}

This article was published in the following Dove Press journal: Cancer Management and Research

\section{Toru Kurata \\ Sachio Fushida \\ Jun Kinoshita \\ Katsunobu Oyama \\ Takahisa Yamaguchi \\ Mitsuyoshi Okazaki \\ Tomoharu Miyashita \\ Hidehiro Tajima \\ Itasu Ninomiya \\ Tetsuo Ohta}

Department of Gastroenterological Surgery, Division of Cancer Medicine, Graduate School of Medical Science, Kanazawa University, Kanazawa, Ishikawa, Japan
Correspondence: Sachio Fushida Department of Gastroenterological Surgery, Division of Cancer Medicine, Graduate School of Medical Science, Kanazawa University, I3-I Takaramachi, Kanazawa, Ishikawa 920-864I, Japan

Tel +8I 762652362

Fax +8I 762344260

Email fushida@staff.kanazawa-u.ac.jp
Background: Characterized by aggressive proliferation, extensive stromal fibrosis, and resulting drug resistance, peritoneal dissemination in gastric cancer remains associated with poor prognosis. Interaction between cancer and stromal cells accelerates tumor progression via epithelial-mesenchymal transition (EMT), which is one of the major causes of tissue fibrosis, and human peritoneal mesothelial cells (HPMCs) play important roles as cancer stroma in peritoneal dissemination. Transforming growth factor- $\beta$ (TGF- $\beta$ ) has a pivotal function in the progression of EMT, and Smad proteins play an important role in the TGF- $\beta$ signaling pathway. Eribulin mesylate (eribulin), a nontaxane microtubule dynamics inhibitor used for the treatment of advanced breast cancer, inhibits EMT changes in triple-negative breast cancer cells. We examined its ability to inhibit tumor progression and EMT changes resulting from the interaction between gastric cancer cells and HPMCs and to act synergistically with 5-fluorouracil (5-FU), a key drug for gastric cancer.

Materials and methods: Proliferation of gastric cancer cells and HPMCs isolated from healthy omentum was assessed by 3-(4,5-dimethylthiazol-2-yl)-2,5-diphenyltetrazolium bromide assay. Following gastric cancer cell/HPMC coculture, EMT markers were detected by immunofluorescence, immunohistochemistry, and Western blotting; invasion assays were performed; and TGF- $\beta$ and Smad phosphorylation were assessed by Western blotting and enzyme-linked immunosorbent assay. A mouse fibrotic tumor xenograft model was established using gastric cancer cell/HPMC cocultures. The effect of eribulin and/or 5-FU was tested in each case.

Results: Eribulin significantly suppressed gastric cancer cell proliferation and EMT changes in MKN-45 gastric cancer cells and HPMCs induced by their interaction in vitro. Eribulin inhibited EMT at much lower concentrations ( $\geq 0.5 \mathrm{nM}$ for MKN-45 and $\geq 0.1 \mathrm{nM}$ for HPMCs) than its half maximal inhibitory concentrations (2.2 nM for MKN-45 and 8.1 nM for HPMCs), and this resulted, at least partly, from the downregulation of TGF- $\beta / \mathrm{Smad}$ signaling. Eribulin administration of $\geq 0.1 \mathrm{mg} / \mathrm{kg}$ suppressed tumor progression $(0.1 \mathrm{mg} / \mathrm{kg}, p=0.02)$, and fibrosis was inhibited by lower dose $(0.05 \mathrm{mg} / \mathrm{kg}, p=0.008)$ in the xenograft model. Furthermore, 0.05 $\mathrm{mg} / \mathrm{kg}$ administration with 5 -FU brought about synergistic antitumor effects $(p=0.006)$.

Conclusion: Low-dose eribulin combined with 5-FU might be a promising therapy for peritoneal dissemination in gastric cancer.

Keywords: peritoneal dissemination, cancer-stromal interaction, human peritoneal mesothelial cell, TGF- $\beta$, Smad, synergism 


\section{Introduction}

Gastric cancer is one of the most common malignancies worldwide, with estimated 951,600 new cases and 723,100 associated deaths in 2012. ${ }^{1}$ Peritoneal dissemination is the most common mode of metastasis in gastric cancer and a critical indicator of poor prognosis. ${ }^{2,3}$ Although various approaches to the treatment of peritoneal dissemination have been assessed, including systemic and/or intraperitoneal chemotherapy, extensive intraoperative peritoneal lavage, and aggressive surgery, satisfactory outcomes have not been achieved. ${ }^{4-9}$ Peritoneal dissemination is characterized by rapid cancer cell infiltration and proliferation accompanied by extensive stromal fibrosis, causing potentially fatal disorders such as bowel obstruction, hydronephrosis, and jaundice and acquired drug resistance. ${ }^{10,11}$ Therefore, new treatment strategies addressing proliferation and fibrosis in peritoneal dissemination of gastric cancer are needed.

Recently, tumor progression has been recognized as the product of an evolving cross talk between cancer cells and the surrounding tissue or tumor stroma. ${ }^{12}$ Fibroblasts in cancer stroma, known as cancer-associated fibroblasts (CAFs), express receptors of several cytokines and chemokines and can produce growth factors as well as cytokines and chemokines themselves, including transforming growth factor- $\beta$ (TGF- $\beta$ ), vascular endothelial growth factor, and hepatocyte growth factor, which affect the invasiveness of cancer cells. ${ }^{13-16}$ Simultaneously, cancer cells also produce stroma-modulating growth factors, including members of the fibroblast growth factor family, platelet-derived growth factor, epidermal growth factor receptor (EGFR), interleukins, and TGF- $\beta$, stimulating stromal cell proliferation and fibrosis. ${ }^{17,18}$ Moreover, fibroblast activation protein (FAP), a transmembrane serine protease highly expressed in CAFs and $>90 \%$ of human epithelial neoplasms, supports tumorigenesis mechanisms such as tissue remodeling and immunosuppression. ${ }^{19}$ We previously reported that human peritoneal mesothelial cells (HPMCs), a monolayer of mesothelial cells covering the peritoneal cavity, play important roles as CAFs of peritoneal dissemination in gastric cancer and contribute to cancer cell growth and fibrosis via epithelial-mesenchymal transition (EMT). ${ }^{20}$

EMT, originally identified as a central process in early embryonic development, is characterized by the loss of the epithelial marker, together with increased expression of mesenchymal markers. ${ }^{21,22}$ EMT correlates well with tumor progression, fibrosis, chemoresistance, and metastasis in many cancers. ${ }^{22-24}$ TGF- $\beta$ is a common initiator of EMT. ${ }^{25}$ In the tumor microenvironment, gastric cancer cell-derived TGF- $\beta$ stimulates CAF proliferation and fibrosis of the stroma, while the production of this cytokine by fibroblasts increases the invasiveness and migration of gastric cancer cells. ${ }^{26,27}$ Furthermore, TGF- $\beta$-mediated activation of HPMCs induces an EMT-like process to adopt the fibroblast- or myofibroblast-like phenotype with FAP expression on the cell membrane, and fibrotic tumors with characteristics of advanced progression have been established by the injection of cocultured gastric cancer cells and HPMCs in a subcutaneous xenograft model. ${ }^{20,28}$ Thus, controlling EMT is considered a promising therapeutic strategy to suppress cancer progression and organ fibrosis, which is often found in metastatic lesion.

Eribulin mesylate (eribulin) is a nontaxane microtubule dynamics inhibitor and has been approved for locally recurrent or metastatic breast cancer and malignant soft tissue tumors. ${ }^{29-31}$ Eribulin prevents normal mitotic spindle formation, leading to irreversible mitotic blockage in $\mathrm{G} 2 / \mathrm{M}$ phase and subsequent cell death by apoptosis. Interestingly, two separate phase III clinical trials involving metastatic breast cancer patients have suggested that eribulin has more pronounced effects on overall survival (OS) than on progressionfree survival. ${ }^{32,33}$ It has recently been reported that eribulin triggers a shift from mesenchymal to epithelial phenotype via reversal of EMT to mesenchymal-epithelial transition (MET) in triple-negative breast cancer, which might lower the incidence of new metastases and prolong OS. ${ }^{34}$

The purpose of the present study was to evaluate eribulin's inhibitory effects on proliferation and EMT changes induced by interaction between gastric cancer cells and HPMCs and to assess its influence on tumor growth and fibrosis using our established fibrotic tumor model. Moreover, we tested for synergistic effects resulting from the administration of eribulin together with another antitumor agent.

\section{Materials and methods} Patients and cell lines

Surgical specimens of human omentum were obtained from patients with no evidence of peritoneal inflammation and/or malignancy who underwent surgery in Kanazawa University Hospital between April and December 2015. Donors were not subjected to chemotherapy or radiation treatment prior to surgery. All patients provided written informed consent prior to participation in the study. The study was approved by the Research Ethics Committee of Kanazawa University. HPMCs were isolated from surgical specimens of human omentum as previously described. ${ }^{35}$ Briefly, small pieces of omentum were surgically resected and incubated in prewarmed phosphate-buffered solution (PBS) containing 
0.125\% trypsin-EDTA (Gibco $® /$ Invitrogen $\AA$; Thermo Fisher Scientific, Waltham, MA, USA) for 30 minutes at $37^{\circ} \mathrm{C}$. The resulting suspension was then centrifuged at $1500 \mathrm{rpm}$ for 5 minutes, and the collected cells were cultured in Roswell Park Memorial Institute (RPMI)-1640 medium (Gibco/Invitrogen) containing $20 \%$ heat-inactivated fetal bovine serum (FBS; Nichirei Biosciences Inc., Tokyo, Japan) at $37^{\circ} \mathrm{C}$ in a humidified atmosphere of $5 \% \mathrm{CO}_{2}$ in air. Cells from the second or third passage after primary culture were used in subsequent experiments.

The human gastric cancer cell lines MKN-45, MKN-74, and MKN-7 were purchased from the Japanese Collection of Research Bioresources Cell Bank (Osaka, Japan). MKN-45 cells were derived from a hepatic metastatic tumor with a microscopic phenotype of a solid type of poorly differentiated adenocarcinoma (por1), MKN-74 cells from a hepatic metastatic tumor with a microscopic phenotype of a moderately differentiated tubular adenocarcinoma (tub2), and MKN-7 cells from metastatic foci to lymph nodes with a microscopic phenotype of a well-differentiated tubular adenocarcinoma (tub1) ${ }^{36,37}$ OCUM-2MD3, a human scirrhous gastric cancer cell line with high peritoneal-seeding activity, was kindly provided by the Department of Surgical Oncology of Osaka City University of Medicine (Osaka, Japan). ${ }^{38} \mathrm{MKN}-45$, MKN-74, and MKN-7 cells were maintained in RPMI-1640 medium supplemented with 10\% FBS, and OCUM-2MD3 cells were cultured in Dulbecco's modified Eagle's medium (Thermo Fisher Scientific) containing 10\% FBS.

\section{Chemicals}

Eribulin was kindly provided by Eisai Co. (Tokyo, Japan), and 5-fluorouracil (5-FU) was purchased from Sigma-Aldrich Co. (St. Louis, MO, USA). Each was reconstituted in PBS to the desired concentrations.

\section{Cell proliferation assay}

The viability of gastric cancer cells and HPMCs treated with eribulin or $5-\mathrm{FU}$ was determined with a standard 3-(4,5-dimethylthiazol-2-yl)-2,5-diphenyltetrazolium bromide (MTT) assay. Briefly, $4 \times 10^{3}$ gastric cancer cells or $8 \times 10^{3}$ HPMCs per well were seeded on 96-well plates and incubated for 24 hours at $37^{\circ} \mathrm{C}$ in a humidified environment containing $5 \% \mathrm{CO}_{2}$. The supernatant was then discarded and replaced with fresh serum-free medium. Eribulin or 5-FU was added to the medium at various concentrations (eribulin, 0.01-100 $\mathrm{nM}$; 5-FU, 0.01-100 $\mu \mathrm{M}$ ), and 72 hours later, the supernatant was discarded, and MTT solution was placed in each well (500 $\mu \mathrm{g} / \mathrm{mL}$ final concentration). Following incubation at $37^{\circ} \mathrm{C}$ for 3 hours, the supernatant was removed, and 150 $\mu \mathrm{L}$ of dimethyl sulfoxide (Wako, Osaka, Japan) was added. The absorbance of each well at $535 \mathrm{~nm}$ was measured using a microplate reader (Model 550; Bio-Rad, Tokyo, Japan). Percentage inhibition was determined by comparing the density of drug-treated cells with that of untreated controls. All experiments were repeated at least three times.

\section{Combination effect of eribulin and 5-FU in vitro}

To evaluate the combined effect of eribulin and 5-FU on cell proliferation in vitro, the combination index (CI) was calculated using MTT assays of MKN-45 cells, according to the following formula: ${ }^{39} \mathrm{CI}=(\mathrm{D}) 1 /(\mathrm{Da}) 1+(\mathrm{D}) 2 /(\mathrm{Da}) 2$, where (Da)1 and (Da)2 are the concentrations required for single agents to achieve a drug effect of a\% (in this experiment, $\mathrm{a}=50$ ), and (D)1 and (D)2 are the concentrations of eribulin and 5-FU, respectively, used in combination to achieve the same effect. The CI values of $<1,1$, and $>1$ indicate, respectively, synergism, additivity, and antagonism of drug combinations.

\section{Indirect coculture and serum-free conditioned medium (SF-CM)}

Indirect cocultures were established as follows: One cell type (MKN-45 cells or HPMCs) was seeded on a 6-well plate, while the other was seeded in 1- $\mu \mathrm{m}$-pore Boyden chambers (BD Falcon, Franklin Lakes, NJ, USA), both at a density of $1 \times 10^{5}$ cells per well or chamber in RPMI medium containing $10 \%$ FBS. After 2 days, the cells were washed twice with PBS, the chambers were placed into the wells of the plates, and the plates were incubated for 5 days in $2 \mathrm{~mL}$ of serum-free RPMI medium with or without $0.05-1.0 \mathrm{nM}$ eribulin or 10 $\mu \mathrm{M} 5$-FU. Both cell types were also cultured alone (control) and exposed to eribulin or 5-FU under the same conditions. The SF-CM was harvested and centrifuged at $1500 \mathrm{rpm}$ for 5 minutes, passed through a $0.45-\mu \mathrm{m}$ filter, and stored at $-80^{\circ} \mathrm{C}$ until needed. The cells were used in subsequent experiments.

\section{Phase-contrast microscopy}

Changes in HPMC morphology were visualized by phasecontrast microscopy. Images were collected using an inverted microscope (Nikon Corporation, Tokyo, Japan).

\section{Immunofluorescence}

To visualize E-cadherin and vimentin in MKN-45 cells and E-cadherin and $\alpha$-SMA in HPMCs the cells were fixed in a 1:1 mixture of methanol and acetone for 10 minutes and 
incubated at $4^{\circ} \mathrm{C}$ overnight with anti-E-cadherin (H-108, rabbit polyclonal IgG; Santa Cruz Biotechnology, Inc., Dallas, TX, USA), anti-vimentin (V9, mouse monoclonal IgG; Santa Cruz Biotechnology, Inc.), and anti- $\alpha$-SMA (1A4, mouse monoclonal IgG; DakoCytomation, Glostrup, Denmark) antibodies, diluted at a ratio of 1:100. Following three PBS washes, slides were incubated with anti-mouse IgG-Alexa Fluor 488 and anti-rabbit IgG-Alexa Fluor 546 (diluted 1:400; Molecular Probes/Invitrogen) antibodies for 1 hour at room temperature. The slides were then stained with Hoechst 33258 for 5 minutes to aid visualization of nuclei, before being observed under a fluorescence microscope (BX50/BX-FLA; Olympus, Tokyo, Japan). The mean fluorescence intensity of $\alpha$-SMA was calculated in five different fields, randomly taken from three different experiments using a BZ-9000 BZII microscope (Keyence, Osaka, Japan).

\section{Western blotting}

Approximately $5 \times 10^{6}$ cells were lysed in RIPA buffer containing 1\% protease inhibitor cocktail (Sigma-Aldrich Co.). Proteins from each sample were subjected to sodium dodecyl sulfate-polyacrylamide gel electrophoresis on $12.5 \%$ gels and transferred to polyvinylidene difluoride membranes (Bio-Rad Laboratories Inc., Hercules, CA, USA), which were blocked with blocking solution (EzBlock containing $0.1 \%$ Tween 20; ATTO Corporation, Tokyo, Japan) at room temperature for 30 minutes. Blots were incubated overnight at $4{ }^{\circ} \mathrm{C}$ with each primary antibody (see below) and subsequently exposed for 1 hour to appropriate horseradish peroxidase (HRP)-conjugated secondary antibodies. The immunoblots were visualized using ECL Plus reagents (GE Healthcare Japan Ltd., Tokyo, Japan) and the light capture system (ATTO Corporation)_and were then quantified using the CS Analyzer system (ATTO Corporation). Primary antibodies against the following proteins were used (diluted 1:200 and supplied by Santa Cruz Biotechnology, Inc., unless otherwise stated): E-cadherin (G-10, mouse monoclonal $\mathrm{IgG})$, N-cadherin (8C11, mouse monoclonal IgG), vimentin (as above), Snail2 (H-140, rabbit polyclonal IgG), TGF- $\beta 1$ (TB21, mouse polyclonal IgG), $\alpha$-SMA (as above, diluted 1:5000), Smad2/3 (E-20, goat polyclonal IgG), and $\beta$-actin (AC-15, mouse monoclonal IgG, diluted 1:10,000; SigmaAldrich Co.). Western blotting was also used to determine whether modulation of TGF- $\beta 1$ transcriptional activity by eribulin correlated with a change in the phosphorylation state of Smad2. Subconfluent HPMCs were incubated with 0.05-1 nM eribulin for 1 hour and then exposed to $5 \mathrm{ng} /$ $\mathrm{mL}$ recombinant human TGF- $\beta 1$ (Sigma-Aldrich Co.) for 1 hour, before Western blotting was performed using an antiphospho-Smad2 antibody (Ser467, rabbit polyclonal IgG, diluted 1:200; Santa Cruz Biotechnology, Inc.).

\section{Invasion assay}

The effects of coculture on MKN-45 cell invasion were established using BD BioCoat Matrigel ${ }^{\circledR}$ Invasion Chambers for 24-well plates (BD Biosciences, Franklin Lakes, NJ, USA), following the manufacturer's instructions. First, the Matrigel was rehydrated using $750 \mu \mathrm{L}$ of serum-free medium, after which $750 \mu \mathrm{L}$ of fresh medium containing 10\% FBS was added to the lower chamber. Next, $0.5 \mathrm{~mL}$ of MKN-45 cells or MKN-45 cells + HPMCs $\left(1 \times 10^{5}\right.$ cells $\left./ \mathrm{mL}\right)$ in serum-free medium were seeded into the upper chamber (both the control membrane and Matrigel membranes were seeded with cells). After 24 hours, cells in the upper chamber were removed, and those having invaded through the Matrigel were fixed in $100 \%$ methanol and stained with hematoxylin. Membranes were removed from inserts and mounted on slides. Using three membranes per group, invading cells were counted in several fields under a microscope with a $10 \times$ objective.

\section{Enzyme-linked immunosorbent assay (ELISA)}

TGF- $\beta 1$ concentration in SF-CM was measured using a Quantikine ELISA (R\&D Systems, Wiesbaden, Germany) according to the manufacturer's instructions.

\section{Mouse xenograft model}

All animal experiments were performed in accordance with the standard guidelines of Kanazawa University. Female immunodeficient BALB/c-nu/nu mice (Charles River Laboratories, Inc., Yokohama, Japan) of 4-6 weeks of age were maintained in a sterile environment. HPMCs were first stained with $4 \mu \mathrm{M}$ PKH26 red fluorescent dye using a cell linker kit (Sigma-Aldrich Co.) following the manufacturer's protocol. MKN-45 cells were cocultured with an equivalent number of HPMCs for 5 days, and a total of $5 \times 10^{6}$ cells in $100 \mu \mathrm{L}$ of RPMI-1640 medium were then subcutaneously injected into the dorsal side of each mouse on day 0 . Eribulin $(0.05,0.1,0.5$, and $1.0 \mathrm{mg} / \mathrm{kg})$ was administered on day 8 and 5 -FU $(20 \mathrm{mg} / \mathrm{kg})$ every 3 days from day 8 into the tail vein. Animals were carefully monitored, and tumor volumes and body weights were measured every 4 days. Tumor volume (V) was calculated according to the formula $\mathrm{V}=\mathrm{AB}^{2} / 2$, where $\mathrm{A}$ is the length of the major axis, and $\mathrm{B}$ is that of the minor axis. On day 28, tumor specimens were collected for histology and immunohistochemistry. 


\section{Histology and immunohistochemistry}

Tumor specimens obtained from subcutaneous tumors were shock-frozen in liquid nitrogen for fluorescence microscopy. Specimens were cryosectioned and mounted on a glass slide, air-dried, and immediately analyzed by fluorescence microscope (Olympus) using a standard filter setup for visualization of PKH26. Tumor specimens were then fixed in $10 \%$ neutral-buffered formalin and embedded in paraffin. Sections were treated with hematoxylin and eosin $(\mathrm{H} \& \mathrm{E})$ and azan stain for the assessment of fibrosis, while antibodies against E-cadherin (H-108, as above, diluted 1:100), vimentin (IS630, mouse monoclonal IgG, ready-to-use; DakoCytomation), and $\alpha$-SMA (as above, diluted 1:100) were used for the immunohistochemical assessment of expression. Deparaffinized sections were pretreated by autoclaving in $10 \%$ citric acid buffer $(\mathrm{pH} 8.0)$ at $120^{\circ} \mathrm{C}$ for 15 minutes. Following treatment with protein block serum (DakoCytomation, Kyoto, Japan) for 10 minutes and 2\% skim milk for 30 minutes to block nonspecific reactions, the sections were incubated with primary antibody at $4^{\circ} \mathrm{C}$ overnight. The EnVision polymer solution (HRP; DakoCytomation) was then applied for 1 hour. Proteins were visualized with $0.02 \%$ 3,3'-diaminobenzidinetetrahydrochloride solution. The sections were then lightly counterstained with hematoxylin and examined using a fluorescence microscope (Olympus). The degree of fibrosis was calculated as a percentage of fibrosis within the whole section in all samples using a BZ-9000 BZII microscope (Keyence).

\section{Statistical analysis}

All data are expressed as means \pm SD. Statistical analyses were conducted using SPSS Version 11.0 (SPSS Inc., Chicago, IL, USA). Comparisons of drug effects were made using one-way analysis of variance or Student's $t$-test. $p$-Values $<0.05$ were considered significant.

\section{Ethics approval and consent to participate}

All procedures followed were in accordance with the ethical standards of the responsible committees on human experimentation (institutional and national) and with the Helsinki Declaration of 1964 and later versions. Written informed consent was obtained from all the patients.

All institutional and national guidelines for the care and use of laboratory animals were followed. Animals were treated in accordance with the Fundamental Guidelines for Proper Conduct of Animal Experiment and Related Activities in Academic Research Institutions, under the jurisdiction of the Ministry of Education, Culture, Sports, Science and Technology of Japan. All animal experiments were approved by the Committee on Animal Experimentation of Kanazawa University.

\section{Results \\ Effects on cellular proliferation of eribulin alone or with 5-FU}

The growth inhibitory effects of eribulin and 5-FU on gastric cancer cells and HPMCs were examined using MTT assays (Figure 1). Half maximal inhibitory concentration $\left(\mathrm{IC}_{50}\right)$ values of $0.5-2.2 \mathrm{nM}$ for eribulin and 4.9-9.7 $\mu \mathrm{M}$ for 5-FU were recorded with respect to cancer cells (those for MKN-45 cells were $2.2 \mathrm{nM}$ and $9.7 \mu \mathrm{M}$, respectively). Values of $8.1 \mathrm{nM}$ and $17.9 \mu \mathrm{M}$, respectively, were observed using HPMCs. The CI was significantly $<1$ at all tested concentrations, revealing a synergism between these drugs in their effect on MKN-45 cells (Table 1).

\section{Coculture-induced EMT changes in HPMCs and MKN-45 cells are inhibited by eribulin}

Control HPMCs had a polygonal and cobblestone-like appearance, whereas HPMCs cocultured with MKN-45 cells demonstrated a spindle-shaped fibroblastic morphology. These morphological changes effected by coculture were attenuated by treatment with $\geq 0.1 \mathrm{nM}$ of eribulin (Figure $2 \mathrm{~A}$ ). Immunofluorescence staining of HPMCs showed that the expression of the mesenchymal marker $\alpha$-SMA increased due to coculture with MKN-45 cells $(p<0.001)$ and was subsequently suppressed by $\geq 0.1 \mathrm{nM}$ of eribulin treatment (0.1 nM $p=0.01,0.5 \mathrm{nM} p<0.001$; Figure 2A and B). Western blotting also demonstrated that the increase in $\alpha$-SMA $(p=0.02)$ and decrease in E-cadherin expression in HPMCs cocultured with MKN-45 cells were mitigated by $\geq 0.1 \mathrm{nM}$ of eribulin treatment $(0.05 \mathrm{nM} p=0.18,0.1 \mathrm{nM} p=0.03,0.5$ $\mathrm{nM} p<0.001,1 \mathrm{nM} p<0.001$; Figure 2C and D).

Although no morphological changes in MKN-45 cells were observed (data not shown), those cocultured with HPMCs showed mesenchymal changes, which were reversed by eribulin administration. Immunofluorescence showed that the expression of vimentin was increased $(p<0.001)$ and that of E-cadherin was decreased in MKN-45 cells cocultured with HPMCs and that these changes were attenuated by $\geq 0.1 \mathrm{nM}$ of eribulin (vimentin $0.1 \mathrm{nM} p=0.03,0.5$ $\mathrm{nM} p<0.001$; Figure $3 \mathrm{~A}$ and B). Western blotting revealed increased N-cadherin, vimentin $(p=0.009)$, and Snail2 
A
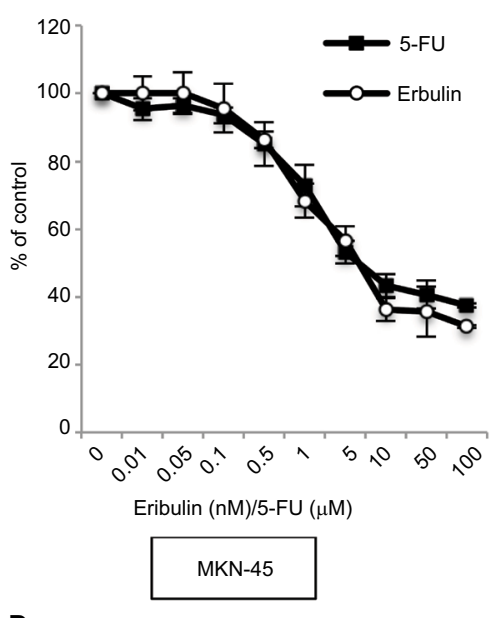

D

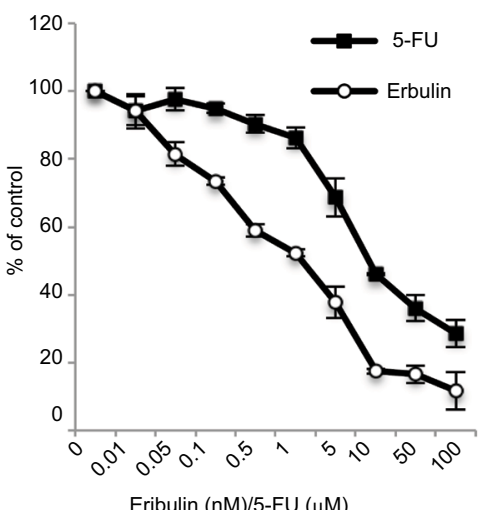

OCUM-2MD3
B

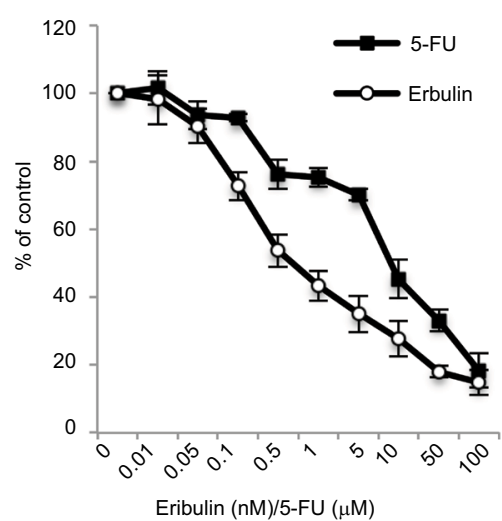

MKN-74

E
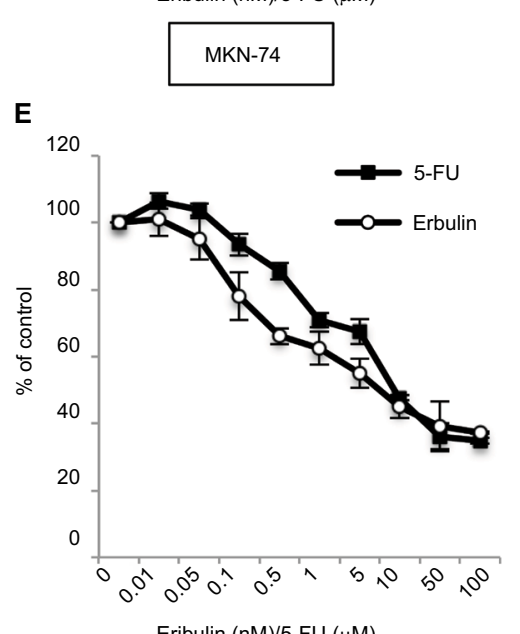

C

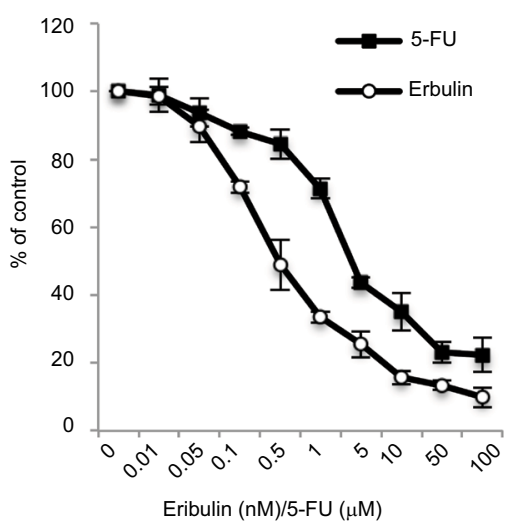

\section{MKN-7}

Figure I Antiproliferative effects of eribulin and 5-FU on gastric cancer cell lines and HPMCs.

Notes: Proliferation in the presence of eribulin or 5-FU was measured by MTT assay. Values shown are means \pm SD of three experiments. Respective IC $\mathrm{C}_{50}$ values of eribulin and 5-FU were $2.2 \pm 0.6$ and $9.7 \pm 3.7 \mu \mathrm{M}$ for MKN-45 cells $(\mathbf{A}), 0.7 \pm 0.2$ and $9.2 \pm 0.9 \mu \mathrm{M}$ for MKN-74 cells (B), $0.5 \pm 0.1$ and $4.9 \pm 1.8 \mu \mathrm{M}$ for MKN-7 cells (C), I.7 \pm 0.4 and $9.1 \pm 0.2 \mu \mathrm{M}$ for OCUM-2MD3 cells (D), and $8.1 \pm 0.6$ and $17.9 \pm 6.4 \mu \mathrm{M}$ for HPMCs (E).

Abbreviations: 5-FU, 5-fluorouracil; HPMCs, human peritoneal mesothelial cells; $I_{50}$, half maximal inhibitory concentration; MTT, 3-(4,5-dimethylthiazol-2-yl)-2,5diphenyltetrazolium bromide.

Table I $\mathrm{Cl}$ values for combinations of eribulin and 5-FU at different ratios, with respect to the MKN-45 cell line

\begin{tabular}{ll}
\hline $\begin{array}{l}\text { Combination ratio: 5-FU }(\mu \mathrm{M}) / \\
\text { eribulin }(\mathrm{nM})\end{array}$ & $\mathrm{Cl}$ value $^{\mathrm{a}}$ \\
\hline $\mathrm{I}: 0.0 \mathrm{I}$ & 0.83 \\
$\mathrm{I}: 0.05$ & $0.7 \mathrm{I}$ \\
$\mathrm{I}: 0.1$ & 0.44 \\
$\mathrm{I}: 0.5$ & 0.66 \\
$\mathrm{I}: \mathrm{I}$ & 0.63 \\
\hline
\end{tabular}

Notes: a $\mathrm{Cl}$ values of $<\mathrm{I}, \mathrm{I}$, and $>\mathrm{I}$ indicate synergism, additivity, and antagonism, respectively.

Abbreviations: $\mathrm{Cl}$, combination index; 5-FU, 5-fluorouracil.

levels and diminished E-cadherin expression in MKN-45 cells cocultured with HPMCs. Treatment with $\geq 0.5 \mathrm{nM}$ of eribulin prevented these EMT-like changes (vimentin 0.05
$\mathrm{nM} p=0.68,0.1 \mathrm{nM} p=0.16,0.5 \mathrm{nM} p=0.008,1 \mathrm{nM} p=0.007$; Figure $3 \mathrm{C}$ and $\mathrm{D})$. Furthermore, the invasiveness of MKN-45 cells was enhanced by coculture with HPMCs $(p=0.02)$ and attenuated by $\geq 0.1 \mathrm{nM}$ of eribulin (MKN-45 $0.1 \mathrm{nM} p=0.02$, $0.5 \mathrm{nM} p<0.001,1 \mathrm{nM} p<0.001 ;$ MKN-45 + HPMCs $0.1 \mathrm{nM}$ $p<0.001,0.5 \mathrm{nM} p<0.001,1 \mathrm{nM} p<0.001$; Figure 3E). The reduced expression of EMT markers was not observed with $10 \mu \mathrm{M} 5$-FU treatment (Figures $2 \mathrm{C}$ and D and $3 \mathrm{C}$ and D).

\section{Eribulin regulates the TGF/Smad pathway}

To examine the mechanism by which eribulin inhibits cellular EMT changes, the effects of coculturing cancer cells with HPMCs and eribulin treatment on the TGF- $\beta /$ Smad pathway were investigated. ELISA demonstrated that TGF- $\beta 1$ concentrations were higher in supernatants from MKN-45 cell/HPMC 

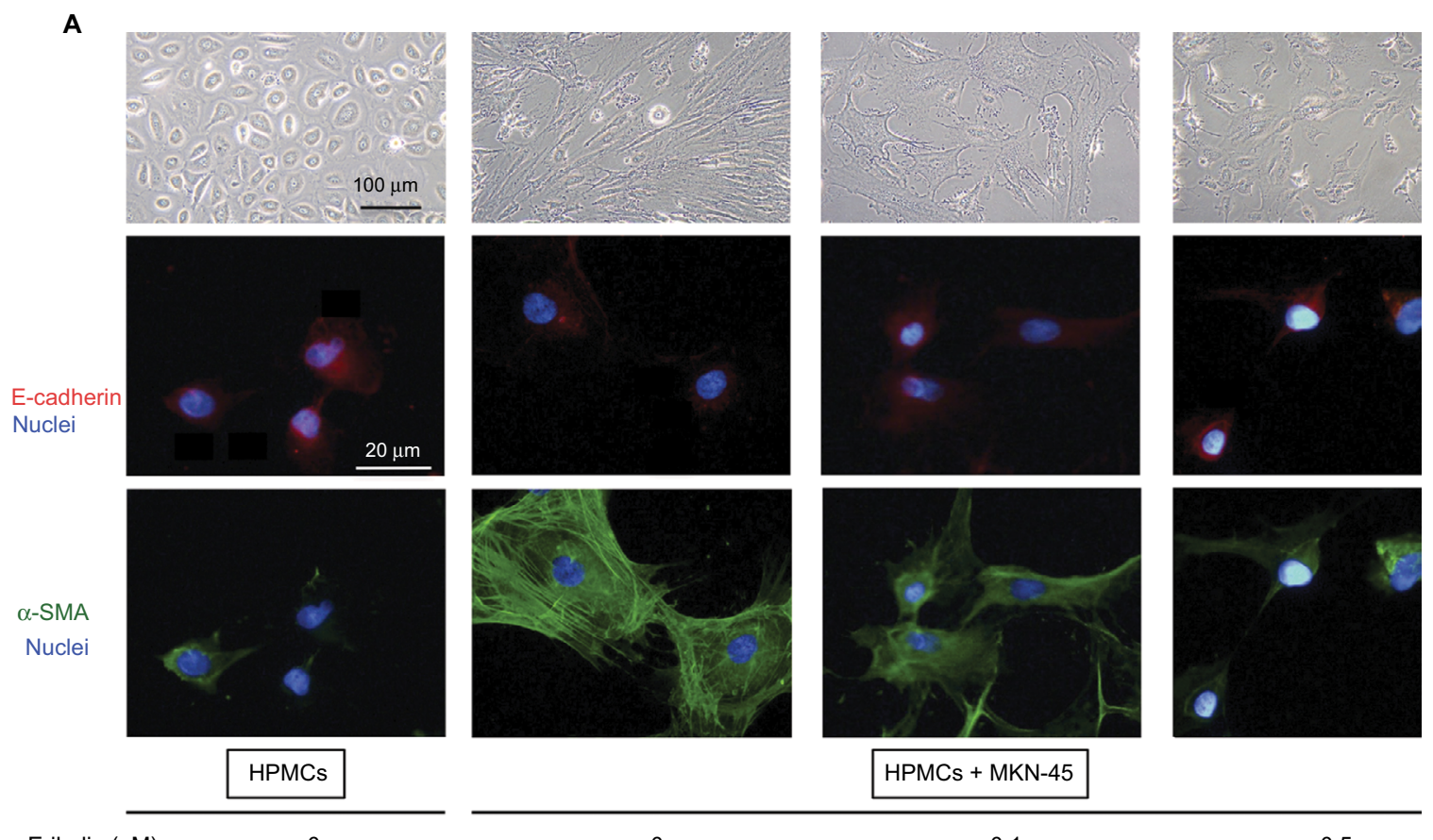

Eribulin (nM)

0

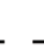

B

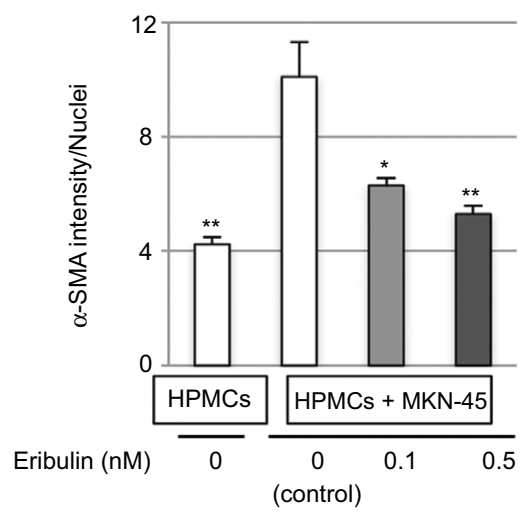

C

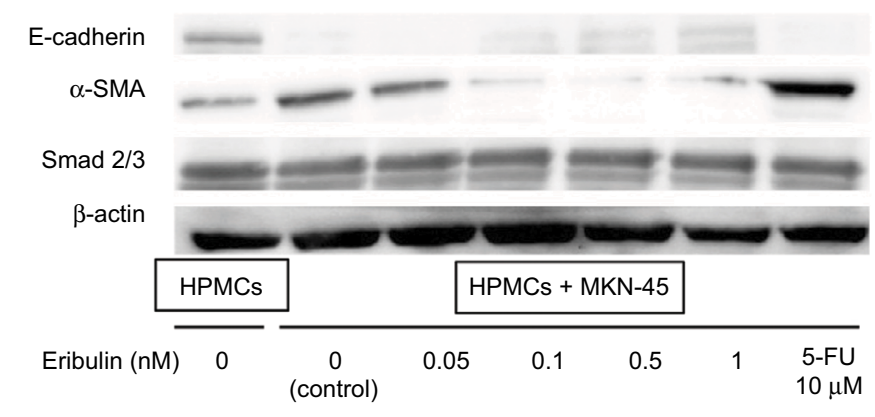

D

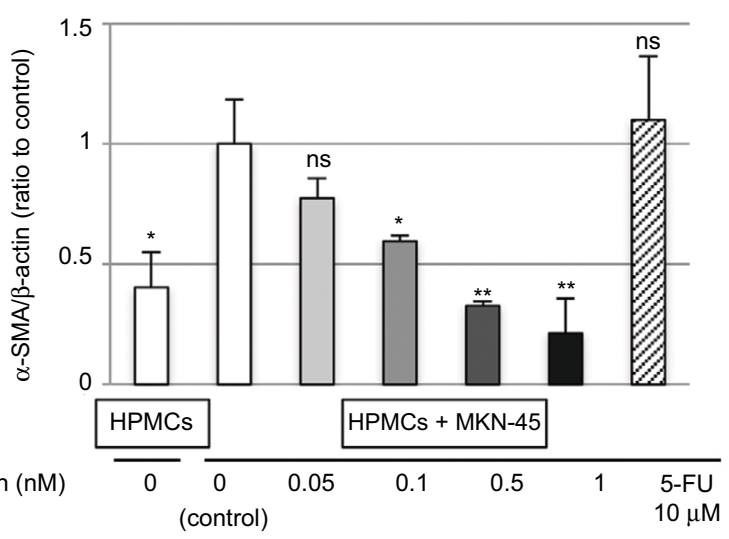

Figure 2 Coculture with MKN-45 cells induces EMT-like changes in HPMCs that are diminished by pretreatment with eribulin.

Notes: (A) Morphological changes in HPMCs observed by phase-contrast microscopy at 40× magnification and immunofluorescence staining of E-cadherin (red) and $\alpha$-SMA (green; original magnification of 400x). (B) Quantitative evaluation of mean $\alpha$-SMA intensity in immunofluorescence images. (C) Western blotting of E-cadherin, $\alpha$-SMA, and Smad2/3; $\beta$-actin was used as a loading control. (D) Densitometry analyses of $\alpha$-SMA expression were performed from three independent experiments. Data are expressed as means \pm SD. $* * p<0.01$ vs control (HPMCs + MKN $-45,0 \mathrm{nM}$ eribulin), ${ }^{*} p<0.05$, ns: not significant.

Abbreviations: EMT, epithelial-mesenchymal transition; 5-FU, 5-fluorouracil; HPMCs, human peritoneal mesothelial cells. 


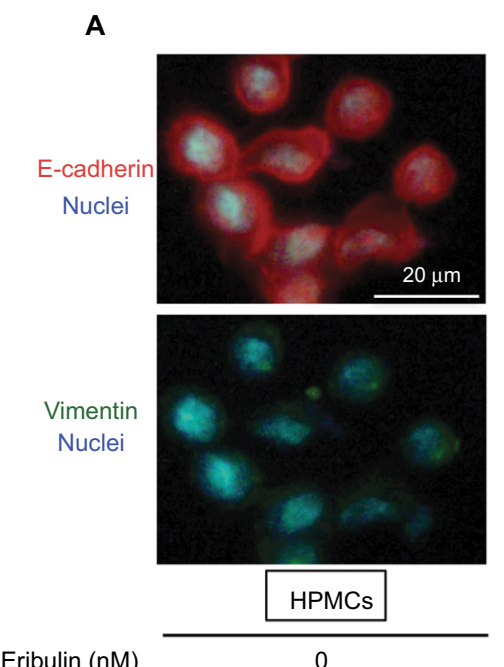

B

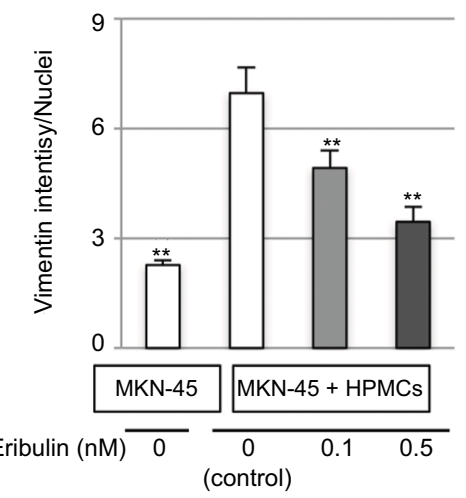

D

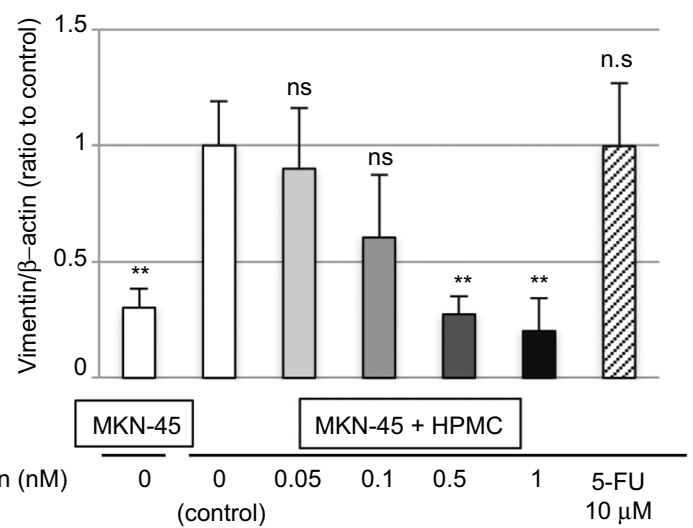
(control)

C
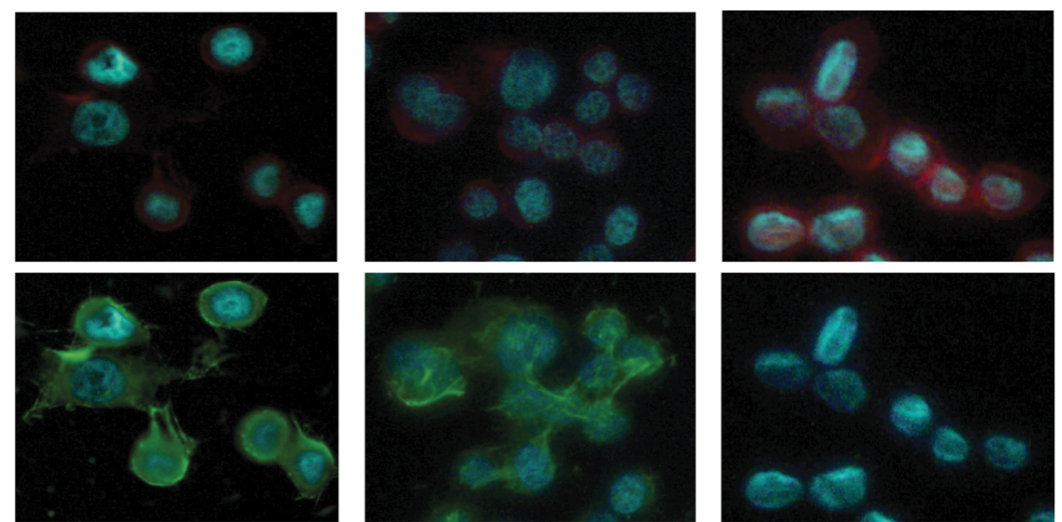

HPMCs + MKN-45

0.1

0.5

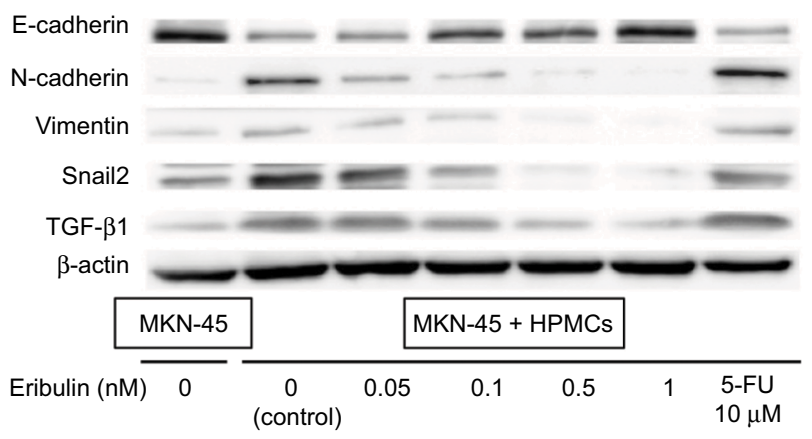

E

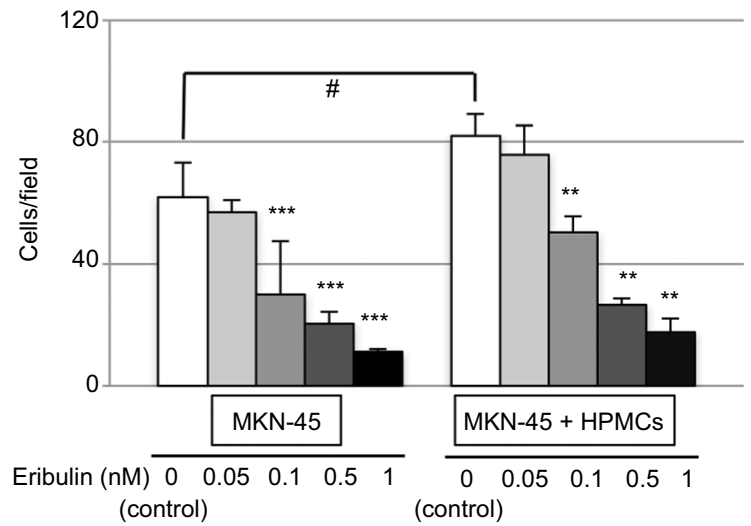

Figure 3 Coculture with HPMCs induces EMT-like changes in MKN-45 cells that are diminished by pretreatment with eribulin.

Notes: (A) Immunofluorescence staining of E-cadherin (red) and vimentin (green) (original magnification of 400x). (B) Quantitative evaluation of mean vimentin intensity in immunofluorescence images. (C) Western blotting of E-cadherin, N-cadherin, vimentin, Snail2, and TGF- $\beta$ I; $\beta$-actin was used as a loading control. (D) Densitometry analyses of vimentin expression were performed from three independent experiments. (E) Invasion assay using Matrigel invasion chambers. Values shown are means \pm SD of three experiments. ${ }^{*} p<0.01$ vs control (MKN-45 + HPMCs, $0 \mathrm{nM}$ eribulin), ${ }^{*} p<0.05$, $* * * * 0.01$ vs control (MKN-45, $0 \mathrm{nM}$ eribulin), $\# p<0.05$, ns: not significant.

Abbreviations: EMT, epithelial-mesenchymal transition; 5-FU, 5-fluorouracil; HPMCs, human peritoneal mesothelial cells; TGF- $\beta$, transforming growth factor- $\beta$. 
cocultures than in those from separate cultures of each cell line (MKN-45 $p=0.03$, HPMCs $p<0.001)$. Moreover, the suppression of TGF- $\beta 1$ production in MKN-45 cell/HPMC cocultures was only detected by $\geq 0.5 \mathrm{nM}$ of eribulin treatment $(0.05 \mathrm{nM}$ $p=0.49,0.1 \mathrm{nM} p=0.06,0.5 \mathrm{nM} p=0.03,1 \mathrm{nM} p=0.03$ ), which reduced proliferation of MKN-45 cells and HPMCs (Figures 1 and 4A). Total expression of Smad2/3 of HPMCs was not affected by coculture with MKN-45 cells (Figure 2C). In contrast, TGF- $\beta 1$ induced increased Smad 2 phosphorylation in HPMCs ( $p<0.001)$, and pretreatment with $\geq 0.1 \mathrm{nM}$ of eribulin significantly decreased this effect $(0.05 \mathrm{nM} p=0.22,0.1 \mathrm{nM}$ $p=0.04,0.5 \mathrm{nM} p=0.01,1 \mathrm{nM} p=0.009$; Figure 4B and C).

\section{Effects of eribulin alone or with 5-FU in a subcutaneous fibrotic xenograft model}

Consistent with our previous report, tumors derived from MKN-45 cell/HPMC cocultures without eribulin treatment were significantly larger than those formed by MKN-45 cells alone 28 days postinoculation, and the implantation of HPMCs in coculture groups was confirmed by PKH26 labeling (Figure 5A and C). H\&E and azan staining revealed that fibrotic areas in tumors from cocultures were larger than those generated by MKN-45 cells alone ( $p=0.02$; Figure $5 \mathrm{C}$ and D). Furthermore, the expression of $\alpha$-SMA and vimentin was increased and that of E-cadherin was decreased in tumors derived from cocultures compared with those resulting from MKN-45 cells alone (Figure 5C).

Coculture tumors in the $\geq 0.1 \mathrm{mg} / \mathrm{kg}$ of eribulin treatment groups were significantly smaller than those in the untreated group $(0.1 \mathrm{mg} / \mathrm{kg} p=0.02,0.5 \mathrm{mg} / \mathrm{kg} p=0.001,1$ $\mathrm{mg} / \mathrm{kg} p<0.001$; Figure $5 \mathrm{~A}$; concentrations $\geq 0.5 \mathrm{mg} / \mathrm{kg}$ not shown). To confirm the combination effect of eribulin and $5-\mathrm{FU}$ in vivo, $0.05 \mathrm{mg} / \mathrm{kg}$ eribulin and/or $20 \mathrm{mg} / \mathrm{kg} 5$-FU was administered to nude mice carrying fibrotic xenograft tumors derived from MKN-45 cell/HPMC cocultures. Although tumor volume in the $0.05 \mathrm{mg} / \mathrm{kg}$ eribulin group was no less than that in the untreated group ( $p=0.59), 20$ $\mathrm{mg} / \mathrm{kg} 5$-FU alone inhibited tumor growth $(p=0.002)$, and combining these drugs did so to an even greater extent (5-FU vs 5-FU + eribulin $0.05 \mathrm{mg} / \mathrm{kg} p=0.006$; Figure 5A). No body weight loss was observed due to treatment with eribulin and/or 5-FU (eribulin $0.05 \mathrm{mg} / \mathrm{kg} p=0.49$, eribulin

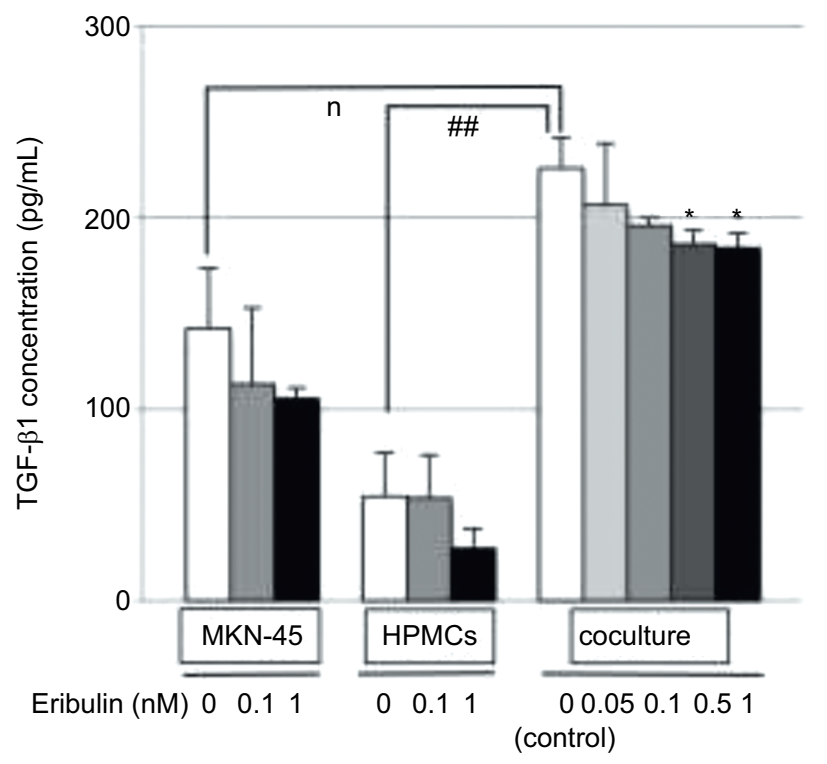

B

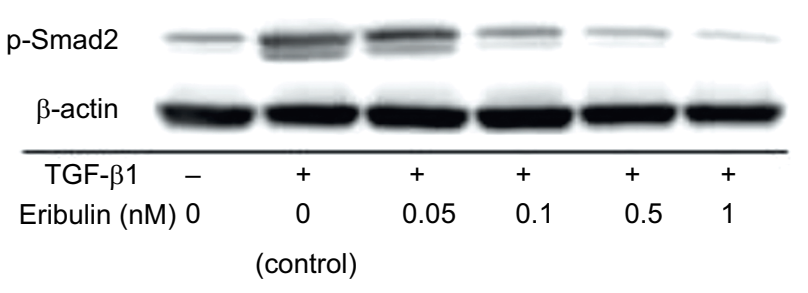

C

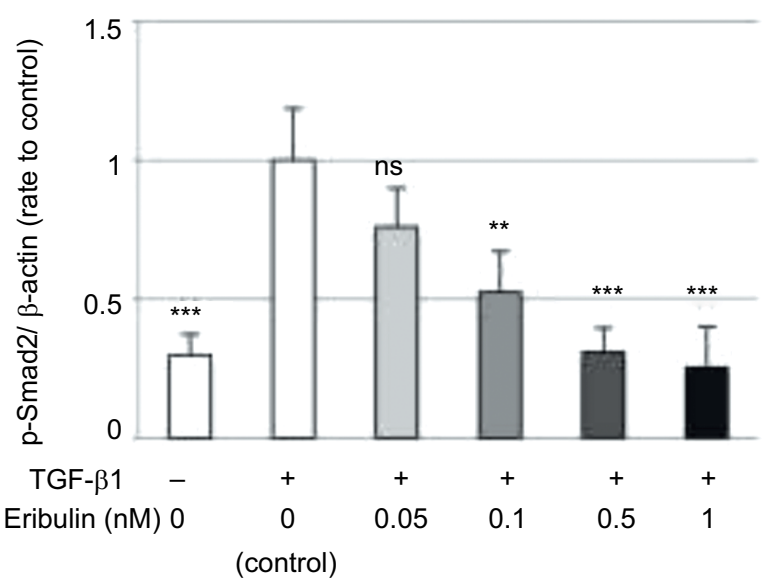

Figure 4 Eribulin downregulates the TGF/Smad pathway by inhibiting Smad2 phosphorylation.

Notes: (A) ELISA of TGF- $\beta$ I levels in the SF-CM from eribulin-treated MKN-45 cell and HPMC cultures and cocultures. Values shown are means \pm SD of three experiments. ${ }^{*} p<0.05$ vs control $(0 \mathrm{nM}$ eribulin), \#p<0.05, \#p<0.01. (B) Western blotting of phosphorylated Smad2 ( $\mathrm{P}-\mathrm{Smad} 2$ ) in HPMCs after TGF- $\beta$ I exposure and pretreatment with eribulin at the indicated concentrations; $\beta$-actin was used as a loading control. (C) Densitometric analyses were performed from three independent experiments. Data are expressed as means \pm SD. ${ }^{*} p<0.05$ vs control (coculture, $0 \mathrm{nM}$ eribulin), ${ }^{* * *} p<0.0 \mathrm{I}$ vs control' (TGF- $\beta \mathrm{I}+, 0 \mathrm{nM}$ eribulin), ${ }^{* *} p<0.05$, ns: not significant.

Abbreviations: ELISA, enzyme-linked immunosorbent assay; HPMCs, human peritoneal mesothelial cells; SF-CM, serum-free conditioned medium; TGF- $\beta$, transforming growth factor- $\beta$. 
A

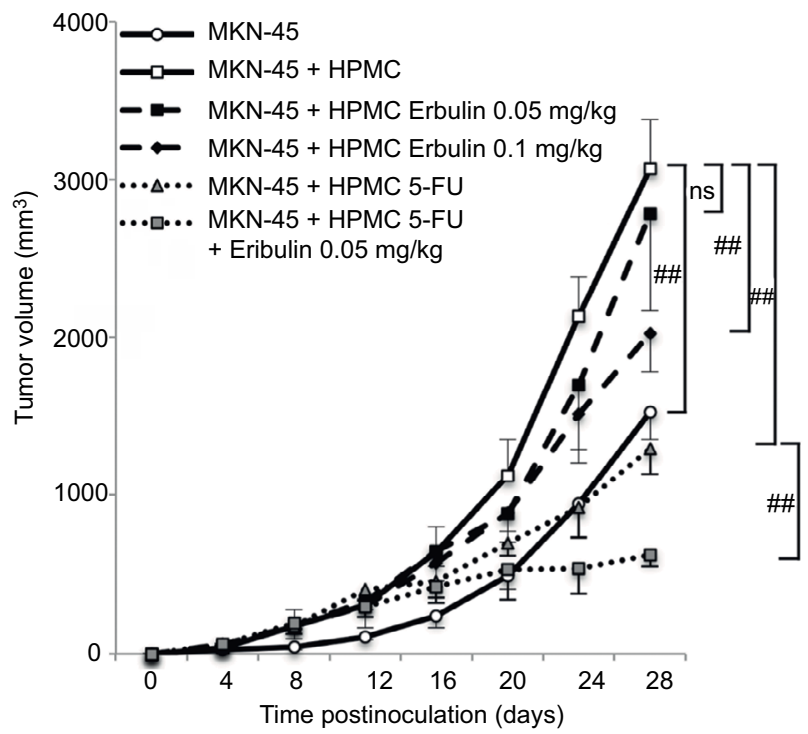

C

H\&E

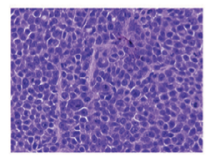

Azan

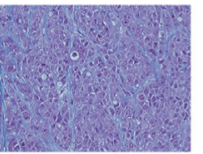

Labeled

HPMCs
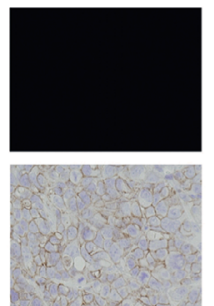

E-cadherin

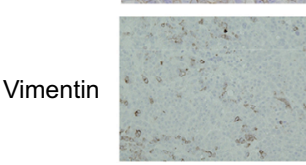

$\alpha-S M A$

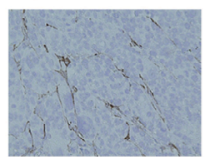

MKN-45
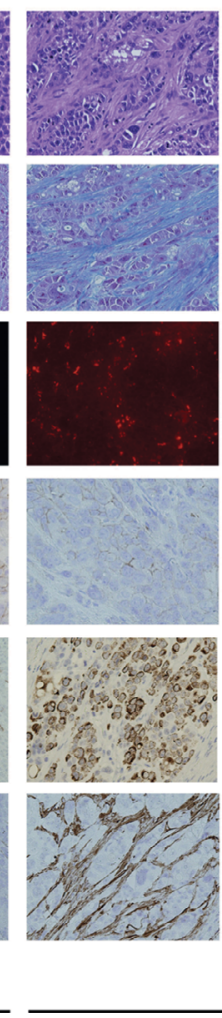
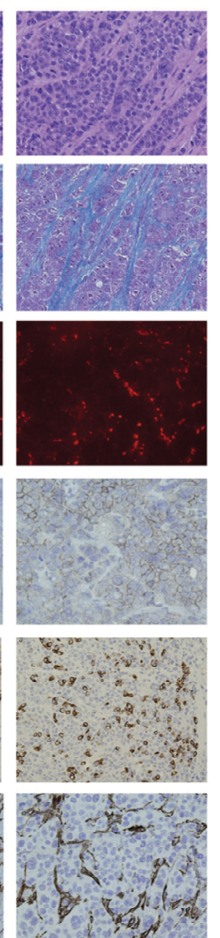

MKN-45 + HPMCs
B

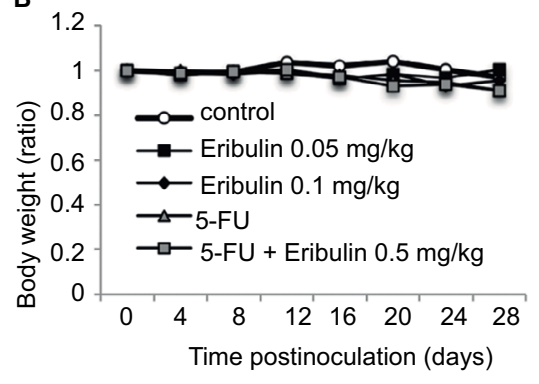

D
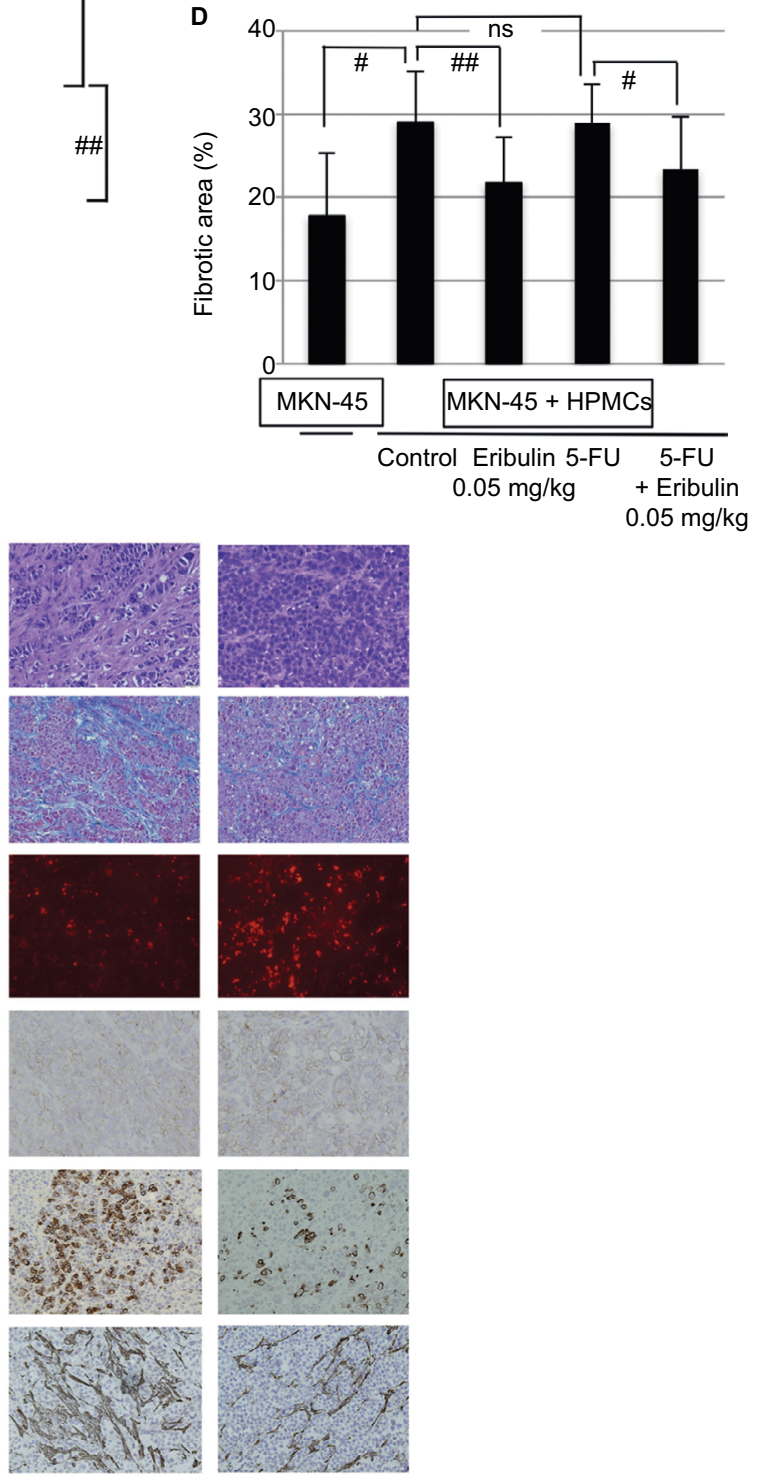

Eribulin $0.05 \mathrm{mg} / \mathrm{kg}$
5-FU

+Eribulin 0.05 mg/kg

Figure 5 Eribulin inhibits growth and EMT of MKN-45 cell/HPMC coculture-derived subcutaneous fibrotic xenograft tumors and demonstrates synergism with 5-FU. Notes: (A) Volumes of tumors derived from MKN-45 cell/HPMC cocultures in mice treated with eribulin and/or 5-FU. Each tumor volume was measured every fourth day $(n=5)$. (B) Body weights of mice carrying tumor xenografts, expressed in relation to preinoculation weights. (C) H\&E and azan staining, fluorescent labeling, and immunohistochemical staining of subcutaneous xenograft tumors 28 days after inoculation (original magnification of 200x). (D) The fibrotic area was measured and shown as percentage (fibrotic area/whole section area) of azan staining in (C). Data are expressed as means \pm SD. \#\# $<0.0$ I, \#p<0.05, ns: not significant.

Abbreviations: EMT, epithelial-mesenchymal transition; 5-FU, 5-fluorouracil; H\&E, hematoxylin and eosin; HPMCs, human peritoneal mesothelial cells; TGF- $\beta$, transforming growth factor- $\beta$. 
$0.1 \mathrm{mg} / \mathrm{kg} p=0.74,5-\mathrm{FU} p=0.38,5-\mathrm{FU}+$ eribulin $0.05 \mathrm{mg} /$ $\operatorname{kg} p=0.39$; Figure 5B). Furthermore, eribulin treatment increased E-cadherin expression, decreased $\alpha$-SMA and vimentin expression, and substantially reduced fibrotic areas in coculture xenograft tumors (control vs eribulin $0.05 \mathrm{mg}$ / $\mathrm{kg} p=0.008,5$-FU vs 5 -FU + eribulin $0.05 \mathrm{mg} / \mathrm{kg} p=0.03$; Figure 5C and D).

\section{Discussion}

In the present study, we examined the effects of eribulin on proliferation and fibrosis in malignant gastric tumors in the context of cancer cell/HPMC interaction in vitro and in vivo. Furthermore, we revealed that combining eribulin with 5-FU, a key drug for gastric cancer, results in synergistic antitumor effects. Therefore, eribulin demonstrates the potential to be an important drug for the treatment of peritoneal dissemination in gastric cancer.

Diffusely infiltrating gastric cancer is characterized by cancer cell infiltration and proliferation accompanied by extensive stromal fibrosis. In peritoneal dissemination, cancer cells initially adhere to HPMCs and then to submesothelial connective tissue after HPMC exfoliation. In the process, cancer cell-derived TGF- $\beta$ activates and induces EMT-like changes in HPMCs, leading cancer cell infiltration into the submesothelial stroma. ${ }^{40} \mathrm{CAFs}$, including activated HPMCs, themselves also produce TGF- $\beta$, inducing EMT and promoting invasion and migration of cancer cells in the microenvironment. ${ }^{41}$ Via TGF- $\beta$ signaling, stromal fibroblasts upregulate gastric cancer cell expression of CD44, which mediates adhesion to HPMCs, and $\alpha 2$ and $\alpha 3$ integrins, key molecules enabling adhesion to submesothelial components. ${ }^{42,43}$ Moreover, activated HPMCs adopt a myofibroblastlike phenotype and infiltrate the submesothelial basement membrane together with cancer cells, promoting proliferative and fibrotic processes as $\mathrm{CAFs} .^{20}$ It has been approved that even MKN-45, which is not derived from a scirrhous cancer and shows medullary tumor in vivo when implanted alone, demonstrated much fibrous and large xenograft tumor after coculturing with HPMCs. ${ }^{20}$ Thus, interaction between gastric cancer cells and CAFs through TGF- $\beta$ and EMT signals results in rapid progression of peritoneal dissemination with extensive stromal fibrosis, contributing to the poor prognosis associated with disseminated gastric cancer.

Accordingly, new strategies based on cancer-stromal interactions should be urgently sought. We previously showed that angiotensin II receptor type 1 blockers, protein-bound polysaccharide $\mathrm{K}$, tranilast, and low-dose paclitaxel can suppress EMT in vitro and in vivo by inhibiting TGF- $\beta$ signaling or the TGF- $\beta /$ Smad pathway, a major mechanism underlying EMT. $^{28,44-46}$ Smad proteins normally bind microtubules in the absence of TGF- $\beta$ and dissociate from them upon TGF- $\beta$ stimulation. Dissociated Smad 2 and Smad 3 proteins become phosphorylated and form complexes with Smad4, before translocating from the cytoplasm to the nucleus, where they activate the transcription of EMT-related genes, including TWIST1, SNAIL1, SNAIL2, and ZEB1, among others. ${ }^{47}$

Taxanes such as paclitaxel stabilize polymerized microtubules and enhance microtubule assembly by extensively binding to their inner surface, leading to cell cycle arrest and cell death. ${ }^{48}$ At doses much lower than that causing cytotoxicity, it appears that by inhibiting microtubule dynamics, paclitaxel can exert cytostatic effects, including the inhibition of Smad2 phosphorylation. ${ }^{46}$ In contrast, eribulin irreversibly binds to the plus ends of microtubules with high affinity and selectivity to suppress dynamic instability by inhibiting microtubule growth with little or no effect on shortening. ${ }^{49}$ This mechanism is thought to explain the much stronger antitumor activity of eribulin on various cancer cell lines and its association with fewer clinical adverse effects, notably peripheral neuropathy, compared with other tubulin inhibitors. ${ }^{29,32,33}$ In this study, eribulin mesylate shows growth inhibitory effects for various gastric cancer cell lines derived from well, moderately, and poorly differentiated adenocarcinomas.

Interaction between MKN- 45 cells and HPMCs mediated by humoral factors enhanced EMT changes in both cell types (cancer cell and CAF), altering HPMC morphology and intensifying MKN-45 cell invasiveness, as well as decreasing expression of epithelial markers and increasing that of mesenchymal markers in both. Eribulin strongly suppressed such changes in both cell lines at lower concentrations than its $\mathrm{IC}_{50}$ and decreased TGF- $\beta 1$ production in MKN-45 cell/ HPMC cocultures. However, eribulin's restriction of TGF- $\beta 1$ production seemed insufficient to explain its inhibitory effect on EMT. Next, the TGF- $\beta /$ Smad pathway was examined in TGF- $\beta 1$-stimulated HPMCs. Eribulin pretreatment significantly decreased TGF- $\beta 1$-induced Smad 2 phosphorylation. Thus, the inhibition of EMT by eribulin appears to occur, at least in part, via downregulation of the TGF- $\beta /$ Smad pathway, and is chiefly based on decreased Smad2 phosphorylation, rather than on reduction of TGF- $\beta 1$ synthesis in cancer cells and HPMCs. Further investigation may reveal that the mechanism by which eribulin inhibits Smad phosphorylation differs from that of paclitaxel, owing to the different microtubule sites to which these molecules bind, as mentioned above. Using a subcutaneous fibrotic xenograft tumor model, we revealed that eribulin can suppress tumor growth and fibrotic 
changes in vivo. Furthermore, 5-FU and eribulin affected MKN-45 cells synergistically, a phenomenon that resulted in remarkably reduced tumor growth in mice without body weight loss, even using an eribulin dose that failed to inhibit tumor progression when administered alone. Therefore, combination therapy comprising low-dose eribulin and cytotoxic antineoplastic agents, such as 5-FU, may be a powerful tool for the treatment of peritoneal dissemination in gastric cancer.

EMT has come to be recognized as an important factor in increased invasiveness and metastasis during cancer progression. In addition, recent evidence indicates that EMT changes result in resistance to several anticancer agents, including EGFR tyrosine kinase inhibitors, cisplatin, gemcitabine, and 5-FU. ${ }^{50-54}$ TGF- $\beta$-mediated EMT processes in a triplenegative breast cancer cell line have been shown to bring about remarkable resistance to 5-FU and eribulin treatment to weaken this resistance by inducing MET. ${ }^{55}$ Moreover, recent reports have demonstrated that eribulin could induce remodeling of abnormal tumor vasculature and improve the perfusion of hypoxic inner tumor areas in breast cancer and soft tissue sarcoma. ${ }^{56,57}$ In general, microtubule stabilizers including taxane have antiangiogenic actions, and microtubule destabilizers such as vinca alkaloids show vascular disrupting activities associated with collapse of existing vasculature. ${ }^{58,59}$ However, eribulin increases inner tumor core perfusion by vascular remodeling, which is caused by altered expression of genes regulating tumor vasculature, such as D114, NOTCH4, and EFNB2, in tumor stroma. ${ }^{56}$ Following peritoneal dissemination, gastric cancer cells surrounded by extensive stromal fibrosis are also exposed to a hypoxic environment, which promotes malignancy through upregulation of TGF- $\beta$ signaling and the hypoxia-inducible factor pathway. ${ }^{60}$ Eribulin could remove the hypoxic stress associated with abnormal tumor microenvironments and increased ability of subsequently administered drugs to reach tumor areas that had previously been poorly perfused in peritoneal dissemination. Thus, the synergism between eribulin and 5-FU might be explained partially by alleviation of 5-FU resistance via not only EMT inhibition, but also elimination of hypoxic stress associated with abnormal tumor microenvironments and improved drug delivery.

A limitation of this study was the possibility that eribulin and 5-FU delivery differed between the subcutaneous fibrotic tumor model and the orthotopic implantation model. Further studies are therefore required to investigate the xenograft model of peritoneal dissemination with organ invasion and fibrosis.

\section{Conclusion}

Our findings indicated that eribulin can significantly suppress EMT changes resulting from interaction between gastric cancer cells and peritoneal cells by inhibiting the TGF- $\beta$ / Smad pathway and can restrict tumor growth and fibrosis in a mouse xenograft model. In addition, eribulin and 5-FU exert synergistic effects on tumor growth. Therefore, a combination of low-dose eribulin and 5-FU might be a promising therapy for peritoneal dissemination in gastric cancer.

\section{Acknowledgments}

We thank Dr T Tomoya, Dr H Saito, and Dr S Terai for advice on how to create in vivo models. We also thank Ms Y Futakuchi and Ms K Yoshida for their excellent technical assistance. This study was supported by a grant-in-aid for JSPS KAKENHI (Grant No. 16K10494).

\section{Disclosure}

The authors report no conflicts of interest in this work.

\section{References}

1. Torre LA, Bray F, Siegel RL, Ferlay J, Lortet-Tieulent J, Jemal A. Global cancer statistics, 2012. CA Cancer J Clin. 2015;65(2):87-108.

2. Chen CY, Wu CW, Lo SS, Hsieh MC, Lui WY, Shen KH. Peritoneal carcinomatosis and lymph node metastasis are prognostic indicators in patients with Borrmann type IV gastric carcinoma. Hepatogastroenterology. 2002;49(45):874-877.

3. Japanese Gastric Cancer Association Registration Committee, Maruyama K, Kaminishi M, et al. Gastric cancer treated in 1991 in Japan: data analysis of nationwide registry. Gastric Cancer. 2006;9(2): $51-66$.

4. Sadeghi B, Arvieux C, Glehen O, et al. Peritoneal carcinomatosis from non-gynecologic malignancies: results of the EVOCAPE 1 multicentric prospective study. Cancer. 2000;88(2):358-363.

5. Koizumi W, Narahara H, Hara T, et al. S-1 plus cisplatin versus S-1 alone for first-line treatment of advanced gastric cancer (SPIRITS trial): a phase III trial. Lancet Oncol. 2008;9(3):215-221.

6. Fushida S, Kinoshita J, Yagi Y, et al. Dual anti-cancer effects of weekly intraperitoneal docetaxel in treatment of advanced gastric cancer patients with peritoneal carcinomatosis: a feasibility and pharmacokinetic study. Oncol Rep. 2008;19(5):1305-1310.

7. Shirao K, Boku N, Yamada Y, et al. Randomized Phase III study of 5 -fluorouracil continuous infusion vs. sequential methotrexate and 5 -fluorouracil therapy in far advanced gastric cancer with peritoneal metastasis (JCOG0106). Jpn J Clin Oncol. 2013;43(10):972-980.

8. Fushida S, Kinoshita J, Kaji M, et al. Phase I/II study of intraperitoneal docetaxel plus S-1 for the gastric cancer patients with peritoneal carcinomatosis. Cancer Chemother Pharmacol. 2013;71(5):1265-1272.

9. Yonemura Y, Kawamura T, Nojima N, et al. Postoperative results of left upper abdominal evisceration for advanced gastric cancer. Hepatogastroenterology. 2000;47(32):571-574.

10. Otsuji E, Kuriu Y, Okamoto K, et al. Outcome of surgical treatment for patients with scirrhous carcinoma of the stomach. Am J Surg. 2004;188(3):327-332.

11. Yashiro M, Chung YS, Nishimura S, Inoue T, Sowa M. Fibrosis in the peritoneum induced by scirrhous gastric cancer cells may act as "soil" for peritoneal dissemination. Cancer. 1996;77(8 Suppl):1668-1675. 
12. Kalluri R, Zeisberg M. Fibroblasts in cancer. Nat Rev Cancer. 2006;6(5):392-401.

13. Yashiro M, Chung YS, Sowa M. Role of orthotopic fibroblasts in the development of scirrhous gastric carcinoma. Jpn J Cancer Res. 1994;85(9):883-886.

14. Schor SL, Schor AM, Grey AM, Rushton G. Foetal and cancer patient fibroblasts produce an autocrine migration-stimulating factor not made by normal adult cells. J Cell Sci. 1988;90(Pt 3):391-399.

15. Olumi AF, Grossfeld GD, Hayward SW, Carroll PR, Tisty TD, Cunha GR. Carcinoma-associated fibroblasts direct tumor progression of initiated human prostatic epithelium. Cancer Res. 1999;59(19): 5002-5011.

16. Pinto MP, Badtke MM, Dudevoir ML, Harrell JC, Jacobsen BM, Horwitz KB. Vascular endothelial growth factor secreted by activated stroma enhances angiogenesis and hormone-independent growth of estrogen receptor-positive breast cancer. Cancer Res. 2010;70(7):2655-2664.

17. Tyan SW, Kuo WH, Huang CK, et al. Breast cancer cells induce cancerassociated fibroblasts to secrete hepatocyte growth factor to enhance breast tumorigenesis. PLoS One. 2011;6(1):e15313.

18. Fushida S, Yonemura Y, Urano T, et al. Expression of hepatocyte growth factor (HGF) and C-met gene in human gastric-cancer cell-lines. Int $J$ Oncol. 1993;3(6):1067-1070.

19. Zi F, He J, He D, Li Y, Yang L, Cai Z. Fibroblast activation protein alpha in tumor microenvironment: recent progression and implications (review). Mol Med Rep. 2015;11(5):3203-3211.

20. Tsukada T, Fushida S, Harada S, et al. The role of human peritoneal mesothelial cells in the fibrosis and progression of gastric cancer. Int $J$ Oncol. 2012;41(2):476-482.

21. Hay ED. An overview of epithelio-mesenchymal transformation. Acta Anat (Basel). 1995;154(1):8-20.

22. Yang J, Weinberg RA. Epithelial-mesenchymal transition: at the crossroads of development and tumor metastasis. Dev Cell. 2008;14(6):818-829.

23. Thiery JP. Epithelial-mesenchymal transitions in tumour progression. Nat Rev Cancer. 2002;2(6):442-454.

24. Uramoto H, Iwata T, Onitsuka T, Shimokawa H, Hanagiri T, Oyama T. Epithelial-mesenchymal transition in EGFR-TKI acquired resistant lung adenocarcinoma. Anticancer Res. 2010;30(7):2513-2517.

25. Nawshad A, Lagamba D, Polad A, Hay ED. Transforming growth factor-beta signaling during epithelial-mesenchymal transformation: implications for embryogenesis and tumor metastasis. Cells Tissues Organs. 2005;179(1-2):11-23.

26. Mahara K, Kato J, Terui T, et al. Transforming growth factor beta 1 secreted from scirrhous gastric cancer cells is associated with excess collagen deposition in the tissue. Br J Cancer. 1994;69(4):777-783.

27. Inoue T, Chung YS, Yashiro M, et al. Transforming growth factor-beta and hepatocyte growth factor produced by gastric fibroblasts stimulate the invasiveness of scirrhous gastric cancer cells. Jpn J Cancer Res. 1997;88(2):152-159.

28. Saito H, Fushida S, Harada S, et al. Importance of human peritoneal mesothelial cells in the progression, fibrosis, and control of gastric cancer: inhibition of growth and fibrosis by tranilast. Gastric Cancer. 2018;21(1):55-67.

29. Towle MJ, Salvato KA, Budrow J, et al. In vitro and in vivo anticancer activities of synthetic macrocyclic ketone analogues of halichondrin B. Cancer Res. 2001;61(3):1013-1021.

30. Jordan MA, Kamath K, Manna T, et al. The primary antimitotic mechanism of action of the synthetic halichondrin E7389 is suppression of microtubule growth. Mol Cancer Ther. 2005;4(7):1086-1095.

31. Schoffski P, Chawla S, Maki RG, et al. Eribulin versus dacarbazine in previously treated patients with advanced liposarcoma or leiomyosarcoma: a randomised, open-label, multicentre, phase 3 trial. Lancet. 2016;387(10028):1629-1637.

32. Cortes J, O'Shaughnessy J, Loesch D, et al. Eribulin monotherapy versus treatment of physician's choice in patients with metastatic breast cancer (EMBRACE): a phase 3 open-label randomised study. Lancet. 2011;377(9769):914-923.
33. Kaufman PA, Awada A, Twelves C, et al. Phase III open-label randomized study of eribulin mesylate versus capecitabine in patients with locally advanced or metastatic breast cancer previously treated with an anthracycline and a taxane. J Clin Oncol. 2015;33(6):594-601.

34. Yoshida T, Ozawa Y, Kimura T, et al. Eribulin mesilate suppresses experimental metastasis of breast cancer cells by reversing phenotype from epithelial-mesenchymal transition (EMT) to mesenchymal-epithelial transition (MET) states. Br J Cancer. 2014;110(6):1497-1505.

35. Yung S, Li FK, Chan TM. Peritoneal mesothelial cell culture and biology. Perit Dial Int. 2006;26(2):162-173.

36. Motoyama T, Hojo H, Watanabe H. Comparison of seven cell lines derived from human gastric carcinomas. Acta Pathol Jpn. 1986;36(1):65-83.

37. Nakatani H, Tahara E, Yoshida T, et al. Detection of amplified DNA sequences in gastric cancers by a DNA renaturation method in gel. Jpn J Cancer Res. 1986;77(9):849-853.

38. Yashiro M, Chung YS, Nishimura S, Inoue T, Sowa M. Establishment of two new schirrhous gastric cancer cell lines: analysis of factors associated with disseminated metastasis. Br J Cancer. 1995;72(5):1200-1210.

39. Chou TC, Talalay P. Quantitative analysis of dose-effect relationships: the combined effects of multiple drugs or enzyme inhibitors. $A d v$ Enzyme Regul. 1984;22:27-55.

40. Zeisberg EM, Potenta S, Xie L, Zeisberg M, Lalluri R. Discovery of endothelial to mesenchymal transition as a source for carcinomaassociated fibroblasts. Cancer Res. 2007;67(21):10123-10128.

41. Yashiro M, Chung YS, Nishimura S, Inoue T, Sowa M. Peritoneal metastatic model for human scirrhous gastric carcinoma in nude mice. Clin Exp Metastasis. 1996;14(1):43-54.

42. Koyama T, Yashiro M, Inoue T, Nishimura S, Hirakawa-YS Chung K. TGF-beta 1 secreted by gastric fibroblasts up-regulates CD44H expression and stimulates the peritoneal metastatic ability of scirrhous gastric cancer cells. Int J Oncol. 2000;16(2):355-362.

43. Nishimura S, Chung YS, Yashiro M, Inoue T, Sowa M. Role of alpha 2 beta 1 - and alpha 3 beta 1 -integrin in the peritoneal implantation of scirrhous gastric carcinoma. Br J Cancer. 1996;74(9):1406-1412.

44. Okazaki M, Fushida S, Harada S, et al. The angiotensin II type 1 receptor blocker candesartan suppresses proliferation and fibrosis in gastric cancer. Cancer Lett. 2014;355(1):46-53.

45. Shinbo T, Fushida S, Tsukada T, et al. Protein-bound polysaccharide $\mathrm{K}$ suppresses tumor fibrosis in gastric cancer by inhibiting the TGF- $\beta$ signaling pathway. Oncol Rep. 2015;33(2):553-558.

46. Tsukada T, Fushida S, Harada S, et al. Low-dose paclitaxel modulates tumour fibrosis in gastric cancer. Int J Oncol. 2013;42(4): $1167-1174$.

47. Dong C, Li Z, Alvarez R Jr, Feng XH, Goldschmidt-Clermont PJ. Microtubule binding to Smads may regulate TGF-beta activity. Mol Cell. 2000;5(1):27-34.

48. Nogales E, Wolf SG, Khan IA, Luduena RF, Downing KA. Structure of tubulin at $6.5 \mathrm{~A}$ and location of the taxol-binding site. Nature. 1995;375(6530):424-427.

49. Smith JA, Wilson L, Azarenko O, et al. Eribulin binds at microtubule ends to a single site on tubulin to suppress dynamic instability. Biochemistry. 2010;49(6):1331-1337.

50. Singh A, Settleman J. EMT cancer stem cells and drug resistance: an emerging axis of evil in the war on cancer. Oncogene. 2010;29(34): $4741-4751$.

51. Thomson S, Buck E, Petti F, et al. Epithelial to mesenchymal transition is a determinant of sensitivity of non-small-cell lung carcinoma cell lines and xenografts to epidermal growth factor receptor inhibition. Cancer Res. 2005;65(20):9455-9462.

52. Zhuo W, Wang Y, Zhuo X, Zhang Y, Ao X, Chen Z. Knockdown of Snail, a novel zinc finger transcription factor, via RNA interference increases A549 cell sensitivity to cisplatin via JNK/mitochondrial pathway. Lung Cancer. 2008;62(1):8-14.

53. Arumugam T, Ramachandran V, Fournier KF, et al. Epithelial to mesenchymal transition contributes to drug resistance in pancreatic cancer. Cancer Res. 2009;69(14):5820-5828. 
54. Wang Z, Li Y, Kong D, et al. Acquisition of epithelial-mesenchymal transition phenotype of gemcitabine-resistant pancreatic cancer cells is linked with activation of the notch signaling pathway. Cancer Res. 2009;69(6):2400-2407.

55. Terashima M, Sakai K, Togashi Y, et al. Synergistic antitumor effects of S-1 with eribulin in vitro and in vivo for triple-negative breast cancer cell lines. Springerplus. 2014;3:417.

56. Funahashi Y, Okamoto K, Adachi Y, et al. Eribulin mesylate reduces tumor microenvironment abnormality by vascular remodeling in preclinical human breast cancer models. Cancer Sci. 2014;105(10): 1334-1342.
57. Kawano S, Asano M, Adachi Y, Matsui J. Antimitotic and non-mitotic effects of eribulin mesilate in soft tissue sarcoma. Anticancer Res. 2016;36(4):1553-1561.

58. Schwartz EL. Antivascular actions of microtubule-binding drugs. Clin Cancer Res. 2009;15(8):2594-2601.

59. Grant DS, Williams TL, Zahaczewsky M, Dicker AP. Comparison of antiangiogenic activities using paclitaxel (taxol) and docetaxel (taxotere). Int J Cancer. 2003;104(1):121-129.

60. Liu HL, Liu D, Ding GR, Liao PF, Zhang JW. Hypoxia-inducible factor- $1 \alpha$ and $\mathrm{Wnt} / \beta$-catenin signaling pathways promote the invasion of hypoxic gastric cancer cells. Mol Med Rep. 2015;12(3):3365-3373.
Cancer Management and Research

\section{Publish your work in this journal}

Cancer Management and Research is an international, peer-reviewed open access journal focusing on cancer research and the optimal use of preventative and integrated treatment interventions to achieve improved outcomes, enhanced survival and quality of life for the cancer patient. The manuscript management system is completely online and includes
Dovepress

a very quick and fair peer-review system, which is all easy to use. Visit http://www.dovepress.com/testimonials.php to read real quotes from published authors. 